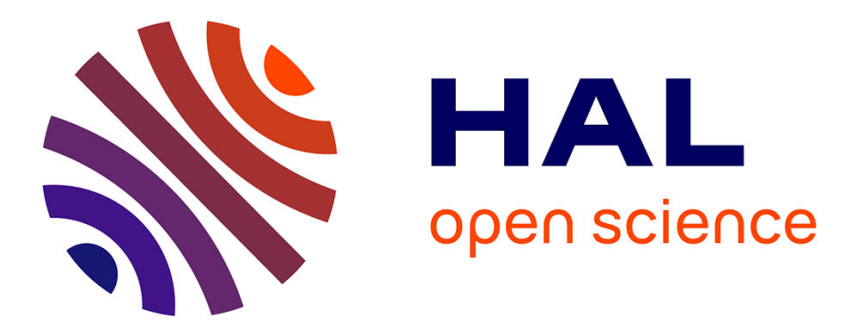

\title{
Tribute to Anne Bertrand (1978-2018): Neuroradiologist, scientist, teacher and friend
}

Didier Dormont, Noam Ben-Eliezer, Ninon Burgos, Olivier Colliot, Fabrizio de Vico Fallani, Marc Dhenain, Stanley Durrleman, Stéphane Epelbaum, Marie-Odile Habert, Isabelle Le Ber, et al.

\section{To cite this version:}

Didier Dormont, Noam Ben-Eliezer, Ninon Burgos, Olivier Colliot, Fabrizio de Vico Fallani, et al.. Tribute to Anne Bertrand (1978-2018): Neuroradiologist, scientist, teacher and friend. Journal de Neuroradiologie / Journal of Neuroradiology, 2019, 46 (2), pp.155-159. 10.1016/j.neurad.2019.01.001 . hal-02265305

\section{HAL Id: hal-02265305 https://hal.inria.fr/hal-02265305}

Submitted on 9 Aug 2019

HAL is a multi-disciplinary open access archive for the deposit and dissemination of scientific research documents, whether they are published or not. The documents may come from teaching and research institutions in France or abroad, or from public or private research centers.
L'archive ouverte pluridisciplinaire HAL, est destinée au dépôt et à la diffusion de documents scientifiques de niveau recherche, publiés ou non, émanant des établissements d'enseignement et de recherche français ou étrangers, des laboratoires publics ou privés. 


\title{
Tribute to Anne Bertrand (1978-2018):
}

\section{neuroradiologist, scientist, teacher and friend}

\begin{abstract}
Anne Bertrand passed away on March 2nd 2018. She was in a touring-skiers group led by a guide and swept by an avalanche in the French Alps. This paper is a tribute to Anne and an attempt, by some of her closest colleagues, to provide an overview of her major contributions. Anne Bertrand was a rising star of the neuroimaging community who traced innovative paths at the interface of basic science and clinical neuroradiology. From the very beginning of her career, she had been interested in the cross-fertilization between research and medical practice. After an MD and a specialization in neuroradiology, she prepared a $\mathrm{PhD}$ in preclinical imaging at the French Atomic Energy Commission (CEA) and at New York University. She was then appointed as Senior Neuroradiologist (at the Pitié-Salpêtrière and then Saint-Antoine Hospital in Paris) and Associate Professor (Sorbonne University). Simultaneously, she continued to develop her research activities in the ARAMIS Laboratory at the Brain and Spinal Cord Institute (ICM).
\end{abstract}

Her main field of interest was neuroimaging of dementias. In a short time, she made important and exceptionally diverse contributions to the understanding, detection, diagnosis and tracking of these disorders (including Alzheimer's disease and fronto-temporal lobar degeneration) using advanced multimodal neuroimaging techniques. They will be a source of inspiration for all of us. Anne was not only an outstandingly bright scientist but also enlightening by her personal qualities: joy, openness, kindness and generosity. 


\section{Introduction}

Anne Bertrand passed away on March $2^{\text {nd }} 2018$ and the neuroimaging community lost one of its most prominent rising stars. She was an outstanding clinical neuroradiologist, a dedicated teacher and a rigorous and creative scientist. Her short carrier was filled with encounters that led to very diverse, rich and fruitful collaborations and friendships. She was particularly implicated in the care and management of patients with neurodegenerative disorders. Her medical training included neuroradiology of course, but also general neurology and neuropathology, demonstrating a genuine and broad interest as well as a great openmindedness. She performed her Master of Science and later her $\mathrm{PhD}$ between France and the USA on animal models of Alzheimer's disease. After her $\mathrm{PhD}$, she focused her research at the interface of computer science and medicine when she joined the ARAMIS Laboratory at the Brain and Spinal cord Institute (ICM). She tutored many students both in medicine and science alike always with a shared respect. She loved every aspects of her job and it truly showed to everyone who knew her. The pleasure of working with Anne was always mutual. This tribute article recapitulates the importance of her work so it may serve as a model of achievement to strive for. We also aim to testify to her family and friends the importance of Anne's contributions to science and medicine, and the inspiration that she was for all of us. 

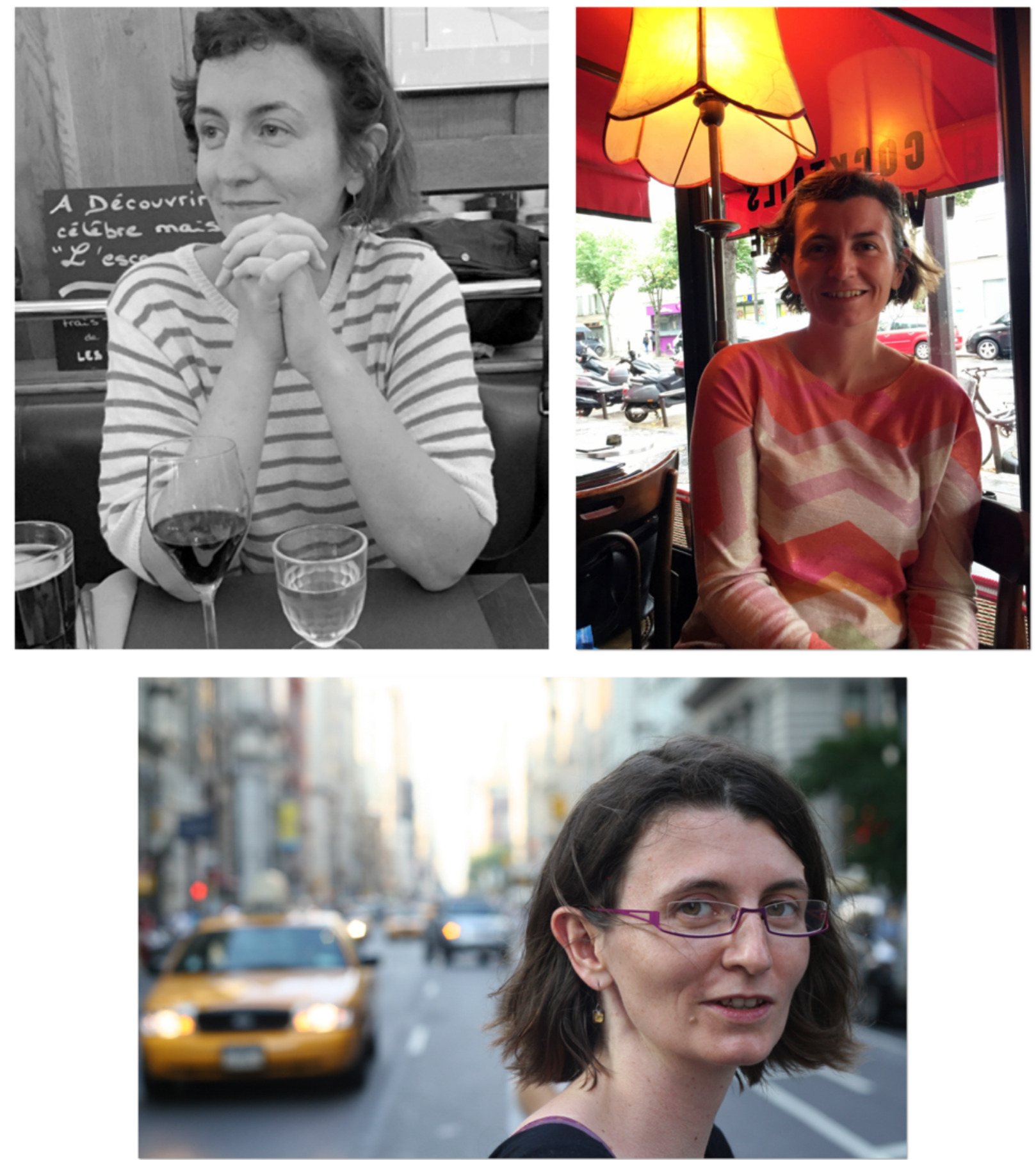

Figure. Anne Bertrand (1978-2018) 


\section{Her medical and scientific career}

Anne first studied at Bichat Hospital and University Paris 7 Diderot Medical School where she early developed a taste for medical imaging. Her successful results at the "Internat" national competitive exam (39 out of more than 3000 participants) allowed her to do her residency in radiology in Paris hospitals (including Pitié-Salpêtrière, Sainte-Anne and Foundation Rothschild hospitals). However, she chose to pass the first six months of her residency in the Neurology Department of Dr T. de Broucker (Delafontaine Hospital, Saint-Denis) where she developed a passion for neurology that never diminished. During her residency, she wrote a neurology textbook for medical school students considered a reference in its domain that was re-edited three times [1]. She was also influenced by six months in the Neuropathology Department of Profs. J.-J. Hauw and C. Duyckaerts (Pitié-Salpêtrière Hospital, Paris) where she acquired a taste of the microscopic features of the central nervous system. She later aimed at reconciling neuropathology and neuroimaging by implementing a histological magnetic resonance imaging (MRI) device at the ICM to acquire microscopically resolved MR images of Alzheimer's disease histological slices.

In 2007, while finishing her medical training, Anne embarked on graduate studies at the French Atomic Energy Commission (CEA) to deepen her exposure to research. She quickly implemented imaging protocols at the microscopic level to visualize amyloid plaques (one of the lesions of Alzheimer's disease), microhemorrhages and microanatomical changes associated to aging. She was among the first scientists to generate images at NeuroSpin, a cutting-edge neuroimaging research center dedicated to high field MRI that had just opened at the time. Anne subsequently expressed interests in pursuing her graduate training in New-York, a city she loved. As part of a PhD thesis co-directed by French and US teams, she joined the laboratories of Drs. Einar Sigurdsson and Youssef Zaim Wadghiri at the New York University (NYU) School of Medicine with the overall goals to develop imaging biomarkers devoted to test 
treatments against Tau pathology (another lesion associated to Alzheimer's disease). This project perfectly fitted her continuous drive to combine basic research with the long-term goals aiming at effective clinical outcome. Her relentless efforts led her to devise a robust imaging protocol based on manganese enhanced MRI (MEMRI) to quantify non-invasively neuronal transport in living subjects. During the same period, Anne naturally took part to ongoing efforts that her NYU colleagues at the Wadghiri lab were devoting to the design of histology coils. She took advantage of the high sensitivity exerted by several homemade MRI probes to push the limit of the microscopic characterization of tissues.

From November 2011 to October 2014, Anne Bertrand worked as "Chef de Clinique Assistant" $(\mathrm{CCA}=$ Fellow $)$ in the department of diagnostic and functional neuroimaging of the Pitié-Salpêtrière hospital. In this position, she was incredibly active in the three parts of the work: clinic (neuroradiology), teaching and research. For the clinical part, she was an excellent neuroradiologist with always a very precise and accurate diagnostic. She was also (very) hard working. She was on call five days a month. She was also involved in the organization of the medical planning of the department which was a difficult task. She had an intense teaching activity at Sorbonne University medical school and mentored radiology residents of the department. When she was CCA, the medical school started sending 6th year students in the Neuroradiology Department (externs). She developed for them (and with them) an extremely interesting activity. She gave every student the objective of submitting a clinical case to the American Journal of Neuroradiology (AJNR). The medical students where fascinated to observe that their work was accepted and published in this high-level international journal. She succeeded to publish with the medical students more than ten clinical cases. In November 2014, she was appointed Senior Neuroradiologist ("Praticien Hospitalier") in the Neuroradiology Department of the Pitié-Salpêtrière hospital. When a PET / MR was installed in the Nuclear Medicine Department in October 2015, Anne was enthusiastically involved in starting this new 
activity. She was very creative about exploring the possibilities offered by this new system. It was the beginning of a rich collaboration between nuclear medicine physicians and neuroradiologists.

In 2013, she joined the ARAMIS Laboratory at the Brain and Spinal Cord Institute (ICM), within the Pitié-Salpêtrière hospital, to continue her research career in parallel to her clinical activities in the department of neuroradiology. Quickly, it became clear to her colleagues that she had outstanding scientific and personal qualities. Within ARAMIS, Anne investigated a new scientific area: the application of advanced computational techniques to neuroimaging of dementia. In 2016, she obtained a secondment at INRIA (the French National Institute of Computer Science) to be able to dedicate half of her time to research within ARAMIS and develop a research program on imaging of fronto-temporal lobar degeneration. At that time, she also officially started supervising her first PhD student, Junhao Wen.

In September 2017, she joined the Radiology Department of Saint-Antoine Hospital in Paris. Her task was to manage activities in neuroradiology in this hospital where a Stroke Center had been recently implemented. She was recruited as a University Associate Professor and it was foreseen that she would become a full Professor of Radiology within a short delay. She was working within a general radiology team, and managed the neuroradiological activites with the very flexible behavior that is necessary while working in a multidisciplinary team. Within a short period, she became an essential team member, obviously highly appreciated by the neurologists, but also by all the other members of the Radiology Department. She promptly revised all imaging acquisition protocols, launched several research projects and organized a team. Simultaneously, she continued her research activities as part of the ARAMIS Laboratory at the ICM. 


\section{Main scientific contributions}

\section{MRI in acute stroke}

During her 6-months internship at the Sainte-Anne hospital (Paris), Anne participated actively to clinical research focused on MRI in acute stroke. At that time, the French Society of Radiology's guide to good use of medical imaging examinations already recommended MRI as the first-line examination for imaging cerebrovascular events or disorders. She first wrote a pedagogic article aimed at physicians involved in stroke patients' care who were unfamiliar with MRI [2]. This publication highlighted the main traps in the MR images when stroke is suspected and provided the technical tips and knowledge necessary for an optimal radiological report. Never defeatist, Anne was convinced that it should be possible to improve the accuracy of diffusion-weighted imaging (DWI) in patients suspected of transient ischemic attack (TIA), by simply increasing image quality. She hypothesized that this would allow the detection of tiny ischemic dots. She set up a new DWI MR sequence and showed that it decreased the rate of false-negative DWI in a series of consecutive TIA patients. By increasing MR image spatial resolution and signal to noise ratio, the so-called optimized DWI sequence could detect tiny bright dots on DWI in patients with transient neurological symptoms. This sequence is still in use 10 years later, and many patients with transient deficit benefited from a definite diagnosis of ischemia, thanks to Anne's publication [3]. Since that time, more than 20 other research groups have relied on Anne's work to further improve DWI for the detection of ischemic lesion in TIA patients and help understand the role of MR in the management of patients suspected of TIA.

Throughout her medical career, Anne continued to be particularly active in clinical research within neuroradiology departments. She was involved in the evaluation of advanced imaging protocols and post-processing techniques to improve neuroradiological practice. In particular, she contributed to the evaluation of a new phase processing technique for the 
detection of cerebral microbleeds [4]. She also published various reviews and case reports (e.g. [5-12]), including the discovery of a new fire hazard for MRI systems [13].

\section{Preclinical imaging of Alzheimer's disease}

Dr. Anne Bertrand was very active in the development of preclinical imaging protocols to follow-up Alzheimer's pathology, a topic that she discovered during her Master of Science and PhD at CEA (French Atomic Energy Commission) and New-York University (NYU). First, she implemented MRI microscopy protocols to detect amyloid plaques, one of the lesions of Alzheimer's disease. She proved that a protocol based on the in vivo infusion of Gadolinium can detect amyloid plaques in mouse models of the disease [14], in primates [15] as well as in human brain specimen. She further used the Gadolinium-staining microscopy technique to detect cerebral microhemorrhages and to demonstrate age-related hippocampal reorganization in primates [16]. Her eagerness to develop new biomarkers for Alzheimer's disease pushed her to work on the detection of tauopathies, the second lesions of Alzheimer's disease. In 2007, Dr. Sigurdsson had just discovered new immunotherapies targeting tau lesions [17] and biomarkers were required to follow-up therapy efficacy. To this end, Anne Bertrand established a novel imaging protocol based on manganese enhanced MRI (MEMRI) that aimed to characterize noninvasively neuronal transport properties in mice $[16,18]$. The strategy she devised proved very effective in demonstrating the first direct in vivo evidence of an association between tauopathy and neuronal transport in genetically engineered mice [19]. The same in vivo monitoring protocol helped demonstrate the regulation of neuronal transport by Tau immunotherapy. Some of her groundbreaking results were featured at the 2012 Alzheimer's Association meeting in Vancouver, BC [20]. Dr Bertrand subsequently took advantage of the high sensitivity exerted by several homemade MRI probes to push the limit of the microscopic characterization of 
tissues. Anne's countless efforts led to French National Research Agency and "Brain \& Spine Institute" grants to pursue these studies.

\section{Neuroimaging of frontotemporal lobar degeneration}

Soon after joining the ARAMIS Laboratory at the Brain and Spinal cord Institute, Anne developed new research activities on neuroimaging of genetic forms of frontotemporal lobar degeneration (FTLD). These are developed in collaboration with Dr Isabelle Le Ber, neurologist. Genetic forms of FTLD are a particularly exciting area for developing neuroimaging biomarkers. Indeed, major genetic mutations causing the disease have been recently identified. Biomarkers are needed to assess future treatments targeting the presymptomatic phase of the disease. Expansion in the gene c9orf72 is major mutation causing both FTLD and amyotrophic lateral sclerosis. The PREVDEMALS study aims to characterize the presymptomatic phase of c9orf72 disease. Based on this cohort, Anne demonstrated, for the first time, that cognitive, anatomical (based on T1-weighted MRI) and microstructural (based on diffusion MRI) are detectable very early in the disease course, in carriers before 40 years of age [21]. In a follow-up paper with her PhD student Junhao Wen, she assessed the potential of an advanced diffusion imaging technique, called neurite orientation dispersion and density imaging (NODDI) for detecting alterations. This technique allows disentangling different forms of diffusion alterations. The study showed that reduction of neurite density is the main type of white matter alteration in the presymptomatic phase of c9orf72 disease and that NODDI has a better sensitivity than conventional diffusion MRI [22]. These results have important implications for the development of therapeutic trials. During the same period, Anne also studied the symptomatic phase of genetic forms of FTLD. Following initial observations by Caroppo et al [23], she showed, in a study with her medical student Fatima Ameur, that atypical white matter abnormalities are common in patients with progranulin mutation but not in those 
with c9orf72 mutation, suggesting a specific vulnerability of the white matter to granulin haploinsufficiency [24]. She was also interested in primary progressive aphasias [25-27]. In collaboration with Dr Marc Teichmann, she studied the prevalence and localization of cerebral microbleeds $(\mathrm{CMB})$ in the three main variants of primary progressive aphasia, demonstrating that $\mathrm{CBM}$ are most prevalent in the logopenic variant and related to an underlying Alzheimer's pathology and do not affect language/cognitive impairment [26].

\section{At the interface of computer science and medicine}

Within the ARAMIS Laboratory, Anne did not just conduct clinical research activities, she also actively took part in the methodological and technical developments.

Anne was involved in the development of Clinica (www.clinica.run), an open-source software platform that aims at making clinical neuroscience easier and more reproducible. A target audience of Clinica is neuroscientists or clinicians conducting clinical neuroscience studies involving multimodal imaging. Anne's contribution was decisive to understand the needs of this audience and define the specifications of the software tool.

Anne also became interested in the development of computational tools to support clinical decisions. In particular, she was quickly convinced of the potential of artificial intelligence and machine learning for improving diagnosis in clinical neuroradiology. She contributed to a series of studies demonstrating the value of machine learning for decision support in dementia. One study showed the value of automatic classification algorithms for assisting differential diagnosis of various neurodegenerative dementias [28,29]. Another study showed that machine learning can help refine the selection of patients in clinical trials [30]. She was also involved in studies using complex network theory to characterize alterations of the structural connectome in Alzheimer's disease [31]. She was instrumental in the development of a research program within ARAMIS dedicated to the construction of disease progression 
models [32]. Last but not least, a firm believer in the importance of Open Science, Anne contributed to the development of a comprehensive open source framework for image analysis and automatic classification from multimodal MRI and PET data [33-35].

Within a computational medicine laboratory such as ARAMIS, Anne's role was unique. She played a key role in identifying important clinical questions, shaping research agendas, designing relevant computational tools and interpreting the outcome of algorithms. 


\section{Memories of Anne}

Anne was a bright scientist and clinician. She was a person of outstanding intelligence and the most wonderful human being.

She wrote that "the world is divided in two: those who build bridges and those who build dams. One day, somebody discovered that dams can also be used to cross the river". Anne loved to build bridges between fundamental research and clinical applications, neuropathology and MRI, computer science and medicine, and between people. Her sharp intuition allowed her to understand scientific approaches far from her background and enrich them with fresh perspectives and new directions. Anne was generous in friendship and was a bridge between many very different persons who all had in common a true friendship for her. She could spend countless hours sharing her knowledge with students and fellows and everyone who met her is indebted to her. She was an inspiring person and her contact and foresight have inspired our researches and will continue to inspire them for a long time.

Anne was the kind of person who makes you want to come to work every morning. Whether you wanted to discuss science, pedagogy or a patient's case she was always available with a smile on her face. She was also a great person to relax, or share a laugh with. In addition to her aforementioned academic achievements, she was an artist, a musician, an esthete. To celebrate great occasions, she was prone to cook herself for $30+$ people or to play the accordion. As her childhood friends commented at her funeral ceremony, "we are all orphaned by her passing". But her memory is also a force that drives every person who met and loved her to keep moving forward and do what they can to honor Anne's legacy. 


\section{Authors}

Didier Dormont ${ }^{1,2,3,4,5,6}, \mathrm{MD}$

Noam Ben-Eliezer ${ }^{7}, \mathrm{MD}, \mathrm{PhD}$

Ninon Burgos ${ }^{1,2,3,4,5}, \mathrm{PhD}$

Olivier Colliot ${ }^{1,2,3,4,5,6,8}, \mathrm{PhD}$

Fabrizio De Vico Fallani ${ }^{1,2,3,4,5}, \mathrm{PhD}$

Marc Dhenain ${ }^{9}$, DVM, PhD

Stanley Durrleman ${ }^{5,1,2,3,4}, \mathrm{PhD}$

Stéphane Epelbaum ${ }^{1,2,3,4,5,8}$, MD, PhD

Marie-Odile Habert ${ }^{10,11}$, MD

Isabelle Le Ber ${ }^{1,2,3,4,8}$, MD, $\mathrm{PhD}$

Jean-François Meder ${ }^{12}$, MD

Yves Menu ${ }^{13}$, MD

Catherine Oppenheim ${ }^{12}, \mathrm{MD}, \mathrm{PhD}$

Youssef Z. Wadghiri ${ }^{14}$, PhD

${ }^{1}$ Institut du Cerveau et de la Moelle épinière, ICM, F-75013, Paris, France

${ }^{2}$ Inserm, U 1127, F-75013, Paris, France

${ }^{3}$ CNRS, UMR 7225, F-75013, Paris, France

${ }^{4}$ Sorbonne Université, F-75013, Paris, France

${ }^{5}$ Inria Paris, Aramis project-team, F-75013, Paris, France

${ }^{6}$ AP-HP, Hôpital de la Pitié-Salpêtrière, Department of Neuroradiology, F-75013, Paris,

France

${ }^{7}$ Department of Biomedical Engineering, Tel Aviv University, Tel Aviv 6997801, Israel

${ }^{8}$ AP-HP, Hôpital de la Pitié-Salpêtrière, Department of Neurology, Institut de la Mémoire et de la Maladie d'Alzheimer (IM2A), F-75013, Paris, France

${ }^{9}$ Centre National de la Recherche Scientifique (CNRS), Université Paris-Sud, Université

Paris-Saclay, UMR 9199, Neurodegenerative Diseases Laboratory, 18 Route du Panorama, F92265 Fontenay-aux-Roses, France

${ }^{10}$ AP-HP, Hôpital Pitié-Salpêtrière, Department of Nuclear Medicine, Paris, France

${ }^{11}$ Laboratoire d'Imagerie Biomédicale, Sorbonne Universités, UPMC Univ Paris 06, Inserm U 1146, CNRS UMR 7371, Paris, France

${ }^{12}$ Department of Neuroradiology, Centre Hospitalier Sainte-Anne, Université Paris-Descartes, INSERM UMR 894, Paris, France.

${ }^{13}$ AP-HP, Saint-Antoine Hospital. Department of Radiology, F-75012 Paris/ France

${ }^{14}$ Center for Advanced Imaging Innovation and Research (CAI2R) \& Bernard and Irene

Schwartz Center for Biomedical Imaging, Department of Radiology, New York University

School of Medicine, New York, New York, 10016, USA 


\section{References}

[1] Bertrand A, Epelbaum S. Neurologie. Elsevier Masson; 2006.

[2] Bertrand A, Oppenheim C, Moulahi H, Naggara O, Rodrigo S, Patsoura S, et al. [Diffusion-weighted imaging of the brain: normal patterns, traps and artifacts]. J Radiol 2006;87:1837-47.

[3] Bertrand A, Oppenheim C, Lamy C, Rodrigo S, Naggara O, Mas JL, et al. Comparison of optimized and standard diffusion-weighted imaging at $1.5 \mathrm{~T}$ for the detection of acute lesions in patients with transient ischemic attack. AJNR Am J Neuroradiol 2008;29:3635. doi:10.3174/ajnr.A0802.

[4] Kaaouana T, Bertrand A, Ouamer F, Law-Ye B, Pyatigorskaya N, Bouyahia A, et al. Improved cerebral microbleeds detection using their magnetic signature on $\mathrm{T} 2 *$-phasecontrast: a comparison study in a clinical setting. Neuroimage-Clin 2016. doi:10.1016/j.nicl.2016.08.005.

[5] Shor N, Amador MDM, Dormont D, Lubetzki C, Bertrand A. Involvement of peripheral III nerve in multiple sclerosis patient: Report of a new case and discussion of the underlying mechanism. Mult Scler Houndmills Basingstoke Engl 2017;23:748-50. doi: $10.1177 / 1352458516687401$.

[6] Ollivier M, Wanono E, Leclercq D, Domont F, Trunet S, Dormont D, et al. Transient reduction in venous susceptibility during posterior reversible encephalopathy syndrome. J Neurol Sci 2015;358:505-6. doi:10.1016/j.jns.2015.09.359.

[7] Bertrand A, Leclercq D, Martinez-Almoyna L, Girard N, Stahl J-P, De-Broucker T. MR imaging of adult acute infectious encephalitis. Med Mal Infect 2017;47:195-205. doi:10.1016/j.medmal.2017.01.002.

[8] Ollivier M, Bertrand A, Clarençon F, Gerber S, Deltour S, Domont F, et al. Neuroimaging features in Posterior Reversible Encephalopathy Syndrome: A Pictorial Review. J Neurol Sci 2016. doi:10.1016/j.jns.2016.12.007.

[9] Leclercq D, Trunet S, Bertrand A, Galanaud D, Lehéricy S, Dormont D, et al. Cerebral tumor or pseudotumor? Diagn Interv Imaging 2014;95:906-16. doi:10.1016/j.diii.2014.08.004.

[10] Bielle F, Navarro S, Bertrand A, Cornu P, Mazeron J-J, Jouvet A, et al. Late dural relapse of a resected and irradiated pineal parenchymal tumor of intermediate differentiation. Clin Neuropathol 2014;33:424-7.

[11] Lancellotti G, Sagot C, Forest A, Greffard S, Bertrand A, Verny M. An Unusual Case of Hemiballism-Hemichorea Associated with Nonketotic Hyperglycemia in Association with a Centrum Semiovale Stroke. J Am Geriatr Soc 2015;63:1720-1. doi:10.1111/jgs. 13577.

[12] Magny E, Sagot C, Cohen-Bittan J, Makdessi S, Bertrand A, Verny M, et al. Probable Creutzfeldt-Jakob Disease Mimicking a Perioperative Stroke in an Elderly Adult. J Am Geriatr Soc 2015;63:1268-9.

[13] Bertrand A, Brunel S, Habert M-O, Soret M, Jaffre S, Capeau N, et al. A New Fire Hazard for MR Imaging Systems: Blankets-Case Report. Radiology 2018;286:568-70. doi:10.1148/radiol.2017162921.

[14] Petiet A, Santin M, Bertrand A, Wiggins CJ, Petit F, Houitte D, et al. Gadolinium-staining reveals amyloid plaques in the brain of Alzheimer's transgenic mice. Neurobiol Aging 2012;33:1533-44. doi:10.1016/j.neurobiolaging.2011.03.009.

[15] Bertrand A, Pasquier A, Petiet A, Wiggins C, Kraska A, Joseph-Mathurin N, et al. MicroMRI study of cerebral aging: ex vivo detection of hippocampal subfield reorganization, 
microhemorrhages and amyloid plaques in mouse lemur primates. PloS One 2013;8:e56593. doi:10.1371/journal.pone.0056593.

[16] Bertrand A, M. Hoang D, Khan U, Z. Wadghiri Y. From Axonal Transport to Mitochondrial Trafficking: What Can We Learn from Manganese-Enhanced MRI Studies in Mouse Models of Alzheimer's Disease? 2011. doi:info:doi/10.2174/157340511794653478.

[17] Asuni AA, Boutajangout A, Quartermain D, Sigurdsson EM. Immunotherapy targeting pathological tau conformers in a tangle mouse model reduces brain pathology with associated functional improvements. J Neurosci Off J Soc Neurosci 2007;27:9115-29. doi:10.1523/JNEUROSCI.2361-07.2007.

[18] Bertrand A, Baron M, Hoang DM, Hill LK, Mendoza SL, Sigurdsson EM, et al. In Vivo Evaluation of Neuronal Transport in Murine Models of Neurodegeneration Using Manganese-Enhanced MRI. Methods Mol Biol Clifton NJ 2018;1779:527-41. doi:10.1007/978-1-4939-7816-8 33.

[19] Bertrand A, Khan U, Hoang DM, Novikov DS, Krishnamurthy P, Rajamohamed Sait HB, et al. Non-invasive, in vivo monitoring of neuronal transport impairment in a mouse model of tauopathy using MEMRI. NeuroImage 2013;64:693-702. doi:10.1016/j.neuroimage.2012.08.065.

[20] Little B, Khan U, Bertrand A, Rajamohamedsait H, Hill L, Hoang DM, et al. Tau immunotherapy improves axonal transport as detected in vivo by manganese-enhanced magnetic resonance imaging. Alzheimers Dement J Alzheimers Assoc 2012;8:P38. doi:10.1016/j.jalz.2012.05.097.

[21] Bertrand A, Wen J, Rinaldi D, Houot M, Sayah S, Camuzat A, et al. Early Cognitive, Structural, and Microstructural Changes in Presymptomatic C9orf72 Carriers Younger Than 40 Years. JAMA Neurol 2018;75:236-45. doi:10.1001/jamaneurol.2017.4266.

[22] Wen J, Zhang H, Alexander DC, Durrleman S, Routier A, Rinaldi D, et al. Neurite density is reduced in the presymptomatic phase of C9orf72 disease. J Neurol Neurosurg Psychiatry 2018. doi:10.1136/jnnp-2018-318994.

[23] Caroppo P, Le Ber I, Camuzat A, Clot F, Naccache L, Lamari F, et al. Extensive white matter involvement in patients with frontotemporal lobar degeneration: think progranulin. JAMA Neurol 2014;71:1562-6.

[24] Ameur F, Colliot O, Caroppo P, Ströer S, Dormont D, Brice A, et al. White matter lesions in FTLD: distinct phenotypes characterize $G R N$ and C9ORF72 mutations. Neurol Genet 2016;2:e47. doi:10.1212/NXG.0000000000000047.

[25] Routier A, Habert M-O, Bertrand A, Kas A, Sundqvist M, Mertz J, et al. Structural, Microstructural, and Metabolic Alterations in Primary Progressive Aphasia Variants. Front Neurol 2018;9:766. doi:10.3389/fneur.2018.00766.

[26] Mendes A, Bertrand A, Lamari F, Colliot O, Routier A, Godefroy O, et al. Cerebral microbleeds and CSF Alzheimer biomarkers in primary progressive aphasias. Neurology 2018;90:e1057-65. doi:10.1212/WNL.0000000000005165.

[27] Teichmann M, Lesoil C, Godard J, Vernet M, Bertrand A, Levy R, et al. Direct current stimulation over the anterior temporal areas boosts semantic processing in primary progressive aphasia. Ann Neurol 2016.

[28] Morin A, Samper-Gonzales J, Bertrand A, Stroer S, Dormont D, Mendes A, et al. Accuracy of MRI classification algorithms in a tertiary memory center clinical routine cohort. Submitt Publ 2019.

[29] Morin A, Samper-Gonzales J, Bertrand A, Cavedo E, Lista S, Dormont D, et al. Accuracy of MRI classification algorithms in a tertiary memory center clinical routine cohort. Alzheimers Dement J Alzheimers Assoc 2017;13:P772-4. doi:10.1016/j.jalz.2017.06.1034. 
[30] Ansart M, Epelbaum S, Gagliardi G, Colliot O, Dormont D, Dubois B, et al. Reduction of recruitment costs in preclinical $\mathrm{AD}$ trials. Validation of automatic pre-screening algorithm for brain amyloidosis. Stat Methods Med Res 2019.

[31] Jacquemont T, De Vico Fallani F, Bertrand A, Epelbaum S, Routier A, Dubois B, et al. Amyloidosis and neurodegeneration result in distinct structural connectivity patterns in mild cognitive impairment. Neurobiol Aging 2017;55:177-89. doi:10.1016/j.neurobiolaging.2017.03.023.

[32] Koval I, Bône A, Louis M, Bottani S, Marcoux A, Samper-Gonzalez J, et al. Similating Alzheimer's disease progression with personalised digital brain models. Submitt Publ 2019.

[33] Samper-González J, Burgos N, Bottani S, Fontanella S, Lu P, Marcoux A, et al. Reproducible evaluation of classification methods in Alzheimer's disease: Framework and application to MRI and PET data. NeuroImage 2018;183:504-21. doi:10.1016/j.neuroimage.2018.08.042.

[34] Wen J, Samper-Gonzales J, Bottani S, Routier A, Burgos N, Jacquemont T, et al. Reproducible evaluation of diffusion MRI features for automatic classification of patients with Alzheimer's disease. Submitt Publ 2019.

[35] Marcoux A, Burgos N, Bertrand A, Teichmann M, Routier A, Wen J, et al. An Automated Pipeline for the Analysis of PET Data on the Cortical Surface. Front Neuroinformatics 2018;12. doi:10.3389/fninf.2018.00094. 